\title{
Alterations in the Expression of Specific Glutamate Receptor Subunits Following Hippocampal LTP in Vivo
}

\author{
Kerrie L. Thomas, ${ }^{1,2}$ Sabrina Davis, ${ }^{3}$ Stephen P. Hunt,${ }^{1}$ and Serge Laroche ${ }^{3,4}$ \\ ${ }^{1}$ Neurobiology Division \\ Medical Research Council Centre \\ Laboratory of Molecular Biology \\ Cambridge CB2 2QH, UK \\ ${ }^{2}$ Division of Neurophysiology \\ National Institute for Medical Research \\ London NW7 1AA, UK \\ ${ }^{3}$ Laboratoire de Neurobiologie de l'Apprentissage et de la Mémoire \\ CNRS URA 1491 Université Paris Sud \\ 91405 Orsay, France
}

\begin{abstract}
Quantitative in situ hybridization revealed that following the induction of hippocampal long-term potentiation (LTP) in the dentate gyrus of freely moving rats, specific increases in the expression of the NR2B subunit of the $\boldsymbol{N}$-methyl-D-aspartate (NMDA) receptor and mGluR1c, a short splice variant of the metabotropic glutamate receptors that are linked intracellularly to phospholipase C (PLC) and protein kinase C (PKC), were seen in the postsynaptic dentate granule cells. There were no changes in the expression of NR2A; NR2C and NR2D NMDA receptor subunits; or mGluR1a, mGluR1b, mGluR5a, and mGluR5b PLC-associated metabotropic receptors. The elevations in NR2B and mGluR1c mRNA were delayed, occurring days after LTP induction. NR2B expression was enhanced significantly by $48 \mathrm{hr}$ after LTP but was starting to decrease toward basal levels by $96 \mathrm{hr}$. The transient increase in the expression of NR2B mirrored the increase in the expression of PKC-sensitive isoforms of the NR1 subunits of the NMDA
\end{abstract}

${ }^{4}$ Corresponding author. receptor we observed previously (Thomas et al. 1994a). The increase in mGluR1c expression was more persistent, showing a significant increase $96 \mathrm{hr}$ after LTP. This study demonstrates that not only are there changes in the expression of individual glutamate receptor subunits but the increases in their expression occur days after the induction of LTP and may reflect so-called late-onset genes that may be important for the maintenance of LTP.

\section{Introduction}

Hippocampal long-term potentiation (LTP) is a persistent, specific, and activity-dependent form of synaptic plasticity that has been demonstrated in the adult mammalian brain and is accepted widely as a potential candidate for the cellular basis for learning and memory (Bliss and Collingridge 1993). It is now well established that activation of the $N$-methyl-D-aspartate (NMDA) receptor is required for the induction of LTP (Collingridge et al. 1983) and that the $\alpha$-amino-3hydroxy-5-methyl-4-isoxazole proprionate (AMPA) receptor plays a major role in its maintenance (Muller et al. 1992). More recently, however, it has been shown that the NMDA receptor mediated synaptic transmission also undergoes lasting potentiation (Bashir et al. 1991; Asztely et al. 1992).

LEARNING \& MEMORY 3:197-208 @ 1996 by Cold Spring Harbor Laboratory Press ISSN1072-0502/96 \$5.00

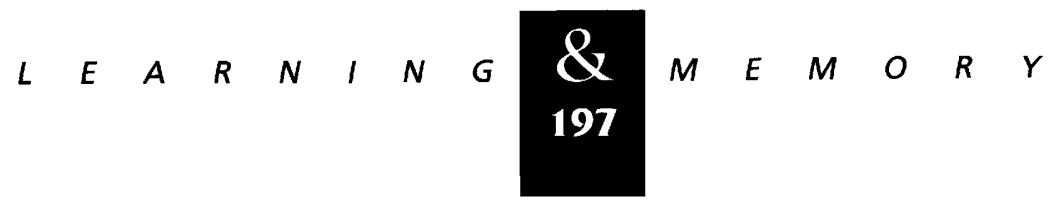




\section{Thomas et al.}

Further, it has been shown, with in vitro studies, that phosphorylation of NMDA receptor subunits by protein kinase $\mathrm{C}$ (PKC) can potentiate NMDA receptor function (Durand et al. 1992; Kutsawada et al. 1992; Urushihara et al. 1992) and this, in turn, suggests that phosphorylation of NMDA receptor is a potential mechanism for the prolonged enhancement of the excitatory postsynaptic potential (EPSP) associated with maintenance of LTP.

The NMDA receptor is an oligomeric receptor, composed of NR1 subunits, which form the lining of the ion channel itself, and modulatory NMDA receptor 2 (NR2) subunits (A-D), in an unknown stoichiometry (Hollmann and Heinemann 1994). Coexpression studies in vitro and the differential expression of individual subunits in the brain reveal a high degree of molecular and functional diversity of the NMDA receptor in which the NR2 subunits are the major determinants of this diversity (Seeburg 1993; Mori and Mishina 1995). We have shown previously there are increases in the expression not only in the $\gamma$ isoform of PKC (Thomas et al. 1994b) during the maintenance of LTP but also in isoforms of the NMDAR1 subunit that are sensitive to PKC phosphorylation (Thomas et al. 1994a). NR2 subunits may also be targets for phosphorylation, and, indeed, synaptic membrane NR2A and NR2B subunits show basal levels of tyrosine phosphorylation in vivo that can undergo further tyrosine phosphorylation by endogenous tyrosine kinases (Lau and Huganir 1995). Because tyrosine phosphorylation plays a significant role in LTP (O'Dell et al. 1991; Grant et al. 1992), it is possible that LTP is correlated with the increased expression of NR2 subunits that are targets for tyrosine phosphorylation.

More recently, the metabotropic glutamate receptors (mGluR's) have been implicated in an LTP-type mechanism, as Bortolotto and Collingridge (1993) have shown that the agonist (1S,3R)-1-aminocyclopentane-1,3-dicarboxylic acid (ACPD) induces a slow onset potentiation in the CA1 region of the slice. This form of potentiation and electrically induced LTP are blocked by the antagonist, (RS)- $\alpha$-methyl-4-carboxyphenylglycine (MCPG) (Bashir et al. 1993; Bortolotto and Collingridge 1993). Since then, replication of the effects elicited by both the agonist and the antagonist has been met with mixed success, where some have been able to replicate the results (Richter-Levin et al. 1994; Manahan-Vaughan and Reymann 1995; Riedel et al. 1995) and others report failure (Chinestra et al. 1993; Manzoni et al.
1994; Ben-Ari and Aniksztejn 1995; Selig et al. 1995) or have shown the effect to be linked with other excitatory amino acid receptors (see Musgrave et al. 1993; O'Connor et al. 1994, 1995; Bortolotto and Collingridge 1995).

To date, eight genes of the $G$ protein linked mGLuR's have been cloned and characterized (for review, see Pin and Bockaert 1995; Pin and Duvoisin 1995). These receptors have been classified into three groups dependent on their signal transduction mechanisms and their pharmacology. Class I type receptors, consisting of $\mathrm{mGluR1}$ and mGluR5, activate phospholipase C (PLC) and subsequently PKC, whereas class II type receptors (mGluR's 2 and 3) are linked negatively to cAMP. Both these receptor classes are sensitive to ACPD, whereas class III type receptors (mGluR's 4, 6, 7, and 8 ) correspond to the L-2-amino-4-phosphorobutyrate (L-AP4) receptor and are insensitive to ACPD (see Pin and Duvoisin 1995). Based on these actions and their differential distribution within the brain, it is more than likely that LTP or similar type mechanisms would be mediated via the class I receptors and this finds support from more recent data using the selective class I receptor agonists (Gerreau and Conn 1995; Davis and Laroche 1996; Fitzjohn et al. 1996).

The expression of LTP is believed to be dependent upon the synthesis of proteins (Frey et al. 1989; Otani and Abraham 1989) and data is accumulating to suggest a differential time course for the expression of genes. Within the first few hours of the induction of LTP, an increase in the expression of certain immediate early genes is observed (Cole et al. 1989; Dragunow et al. 1989; Wisden et al. 1990; Abraham et al. 1991). This is followed by expression of presynaptic vesicle proteins such as syntaxin (Smirnova et al. 1993; Lynch et al. 1994) and synapsin (Hicks et al. 1996) and calcium-dependent kinases such as $\alpha \mathrm{CaMKII}$ and $\gamma \mathrm{PKC}$ (Thomas et al. 1994b). At later time points, e.g., $24 \mathrm{hr}$ after the induction of LTP, expression of the calcium-independent kinases ERK2 and raf-B occurs (Thomas et al. 1994b), and at $48 \mathrm{hr}$, expression of the NMDA receptor subunit NR1 is increased (Thomas et al. 1994a). Based on these data, we investigated the expression of the NR2 subunits of the NMDA receptor, which are subject to tyrosine phosphorylation, and the class I type mGluR subtypes that are coupled to the activation of PKC, an event that takes place downstream to the induction of LTP (Malenka et al. 1989; Malinow et al. 1989; Klann et al. 1993).

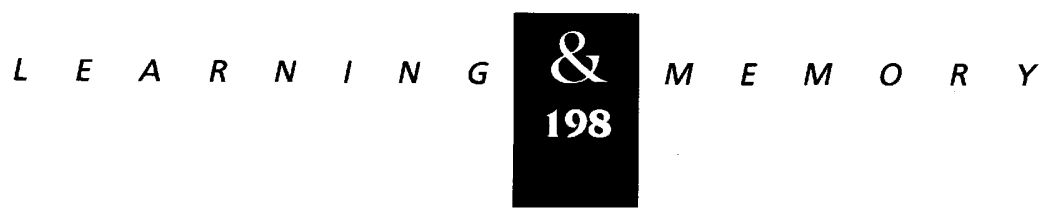




\section{Materials and Methods}

\section{LTP INDUCTION}

Adult male Sprague-Dawley rats $(n=27)$ were anesthetized [sodium pentobarbitone, $60 \mathrm{mg} / \mathrm{kg}$, intraperitoneally (i.p.)] and prepared for chronic recording as described previously (Laroche et al. 1989). Recording electrodes (two 62- $\mu \mathrm{m}$ diameter nichrome wires, placed inside a tube and stag. gered $200 \mu \mathrm{m}$ point to point) were lowered into the hilus of the dentate gyrus (coordinates: Bregma-4.2 mm, Midline-2.5 mm) under physiological control. Concentric bipolar stimulating electrodes (a 150- $\mu \mathrm{m}$ diameter stainless steel wire inserted inside a 300- $\mu \mathrm{m}$ microtube) were lowered into the angular bundle of the perforant path (coordinates: Bregma-7.8 mm, Midline-4.4 mm) until a positive going field potential was elicited. Dental acrylic, anchored to the skull by screws, encased the electrodes and held the assembly in place. Rats were allowed $\sim 10$ days to recover from surgery. During this period they were habituated to the recording chamber $(25 \times 25 \times 50$ $\mathrm{cm}$ ) for $30 \mathrm{~min}$ a day. Recording and stimulating cables were relayed at the top of the chamber through a multichannel rotating commutator. Forty test pulses ( $100 \mu \mathrm{s})$ to the perforant path were delivered at a rate of 1 per $30 \mathrm{sec}$ on each experimental day commencing 20 min after the start of each session. The test intensity was adjusted to give a population spike of approximately $1 \mathrm{mV}$. On day 3 , the recording session was lengthened and LTP was induced by delivery of six series, at 2-min intervals, of six high-frequency trains ( $400 \mathrm{~Hz}$ for $20 \mathrm{~ms}$ ) at $0.1 \mathrm{~Hz}$. To increase the number of potentiated synapses the stimulus intensity was increased during the tetanus to give a population spike of $\mathbf{8 0 \%}$ of its maximum. Lowfrequency testing was then resumed for $30 \mathrm{~min}$ and for $20 \mathrm{~min}$ each day for the next 4 days. The same protocol was applied to stimulated controls except that each high-frequency train on day 3 was replaced by a single shock of high intensity. In another group, high-frequency stimulation was given in the presence of the selective competitive NMDA receptor antagonist 3-[(RS)-2-carboxypiperazin-4-yl]-propyl-1-phosphonic acid (CPP). Two hours prior to tetanic stimulation, CPP was injected i.p. at a dose of $10 \mathrm{mg} / \mathrm{kg}$.

Field potentials were evoked by test pulses at $0.033 \mathrm{~Hz}$ to the perforant path (via a photically isolated constant current unit) and were recorded through field effect transistors placed on the rats heads'. Signals were amplified, filtered (bandpass from $0.1 \mathrm{~Hz}-3 \mathrm{KHz}$ ), digitized at $12.5 \mathrm{KHz}$ and averaged in groups of four for storage on disc and off-line analysis. The EPSP was measured by calculating the maximum slope of the early rising phase and the amplitude of population spike was measured by drawing a tangent from peak to peak and dropping a line to its maximum negative peak. For each individual rat, the data were expressed as a percent change of the mean baseline value obtained before high-frequency stimulation (days 1-3).

\section{IN SITU HYBRIDIZATION}

Rats were killed by stunning and decapitation after the end of the recording session: $2 \mathrm{hr}, 1,2$, and 4 days after the induction of LTP, and whole brains were rapidly removed and frozen on dry ice. For the LTP group $n=3$ at $2 \mathrm{hr}, n=3$ at $24 \mathrm{hrs,}$ $n=6$ at $48 \mathrm{hr}$, and $n=4$ at $96 \mathrm{hr}$. For the stimulated controls $n=2$ at $2 \mathrm{hr}$, and $n=1$ at 24 and 48 hr, and $n=4$ at $96 \mathrm{hr}$. For the group where the tetanus was given in the presence of CPP, $n=3$ at 4 days. The brains were stored at $-70^{\circ} \mathrm{C}$ until sectioned. Fifteen-micron sections were cut at $-20^{\circ} \mathrm{C}$ on a freezing microtome (Bright Instruments) and thaw-mounted onto poly-L-lysine (hydrobromide mol. wt. $>300,000$, Sigma) coated glass slides $(0.02 \mathrm{mg} / \mathrm{ml}$ diethyl pyrocarbonate treated water). The sections were air-dried for not less than $30 \mathrm{~min}$, fixed in $4 \%$ paraformaldehyde in 0.1 м PBS ( $\mathrm{pH} 7.4$ ) for $5 \mathrm{~min}$, rinsed in PBS for 1 min, delipidated in $70 \%$ ethanol for $4 \mathrm{~min}$, and stored in $95 \%$ ethanol at $4^{\circ} \mathrm{C}$.

In situ hybridization using ${ }^{35}$ S-labeled DNA oligonucleotide probes ( $45 \mathrm{mers}$ ) was performed essentially as Wisden et al. (1991). The short isoforms of mGluR1, mGluR1b and mGluR1c, were generated by alternative splicing, at least one exon from a single gene mGluR1a; mGluR1b had an 85bp sequence containing a terminal codon inserted at position 2652 of mGluR1a, whereas mGluR1c was identical to mGluR1a except that the last 312 amino acids are replaced by 10 residues (Pin et al. 1992; Tanabe et al. 1992). mGluR5b was generated by the inclusion of a 96-bp insertion at position 2627 of mGluR5a, resulting in a protein that was 32 amino acids longer than mGluR5a (Minakami et al. 1993). Oligonucleotides complementary to nucleotides 3004-3048 of mGluR1a (Masu et al. 1991), 2653-2697 of mGluR1b (Tanabe et al. 1992), 2676-2720 of mGluR1c (Pin et al.

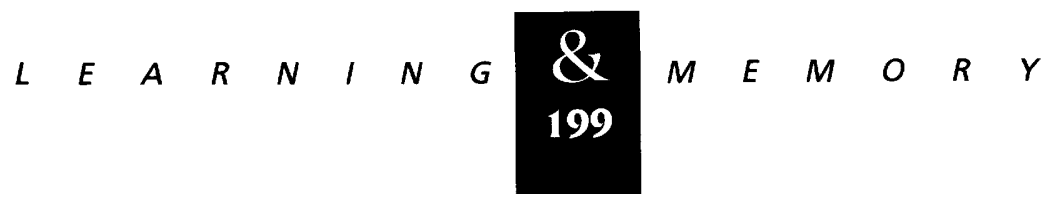


Thomas et al.
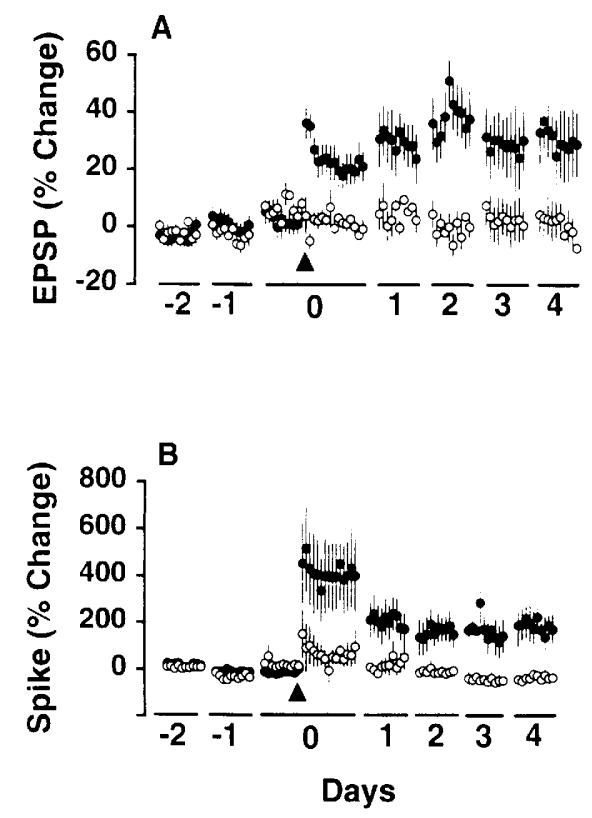

Figure 1: Long-term potentiation in the perforant path projection to the dentate gyrus in freely moving rats. The initial slope of the EPSP $(A)$ and amplitude of the population spike $(B)$ is plotted as a function of time and as a percentage change from the mean value obtained on days $1-3$ before high-frequency stimulation ( or highfrequency stimulation during CPP application $(O, n=3)$. Tetanic stimulation is indicated by an arrow. Each point on the graph represents the average of four consecutive evoked responses. All rats in the experiment are represented in the graph. As rats were sacrificed at different time points, the numbers are reduced across time: at 2 hr post LTP, $n=16$; at 1 day post-LTP, $n=13$; at 2 days post LTP, $n=10$; and at 4 days post-LTP (also represented on day 3 ), $n=4$.

1992), 2875-2919 of mGluR5a (Abe et al. 1992), and 2629-2673 of the coding sequence of mGluR5b (Minakami et al. 1993) were generated on an ABI DNA synthesizer. Specific oligonucleotides for NR2A, NR2B, NR2C, and NR2D were also synthesized identical to those reported by Monyer et al. (1994). Hybridized sections were apposed initially to Kodak BioMax film before being dipped in photographic emulsion (Ilford K5) to reveal the cellular distribution of the mRNA. Silver grain density was assessed bilaterally in the dentate gyrus of the hippocampus using an MCID package from Imaging Research Inc. (Canada). The density of silver grains over nine individual dentate granule cells was measured in one chosen field, namely the middle of the ventral blade of the dorsal dentate gyrus. Counts in at least two pairs of adjacent sections from each rat were performed.
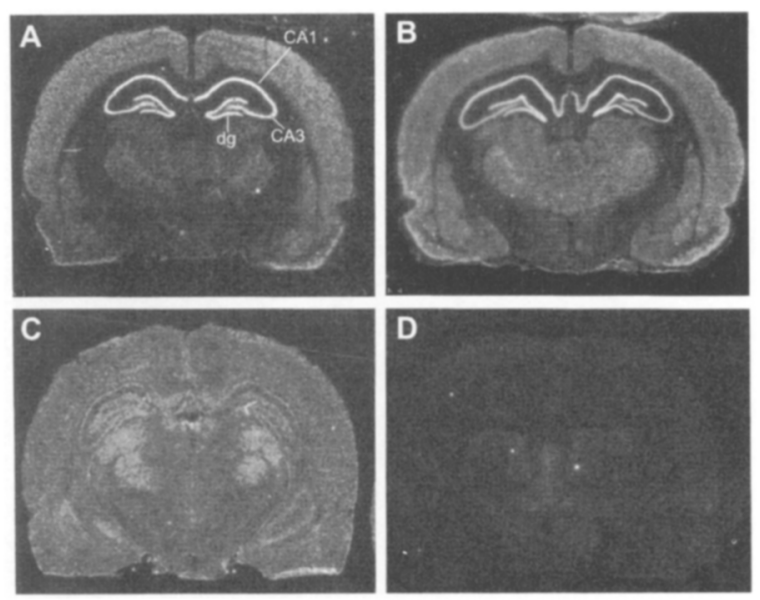

Figure 2: Distribution of mRNAs for NR2 subunits of the NMDA receptor NR2A $(A), N R 2 B(B), N R 2 C(C)$, and NR2D $(D)$. Autoradiograms from film images after in situ hybridization of coronal brain sections cut at the level of the hippocampus are shown. Increased whiteness in the photographs printed directly from film corresponds to higher levels of hybridization of the specific ${ }^{35} \mathrm{~S}$-radiolabeled DNA probes. High NR2A and NR2B expression is detected in all neuronal cell layers of the hippocampus. The signal for NR2C mRNA is more diffuse than those for NR2A and NR2B and indicates localization to nonglutamatergic cells. There was not evident expression of NR2D in the adult hippocampus. (dg) Granule cell layer of the dentate gyrus; (CA1 and CA3) subregions of the pyramidal cell layer of the hippocampus.

One section of each pair representing the total grain density and another representing nonspecific grain density, were defined by inclusion of 100 times excess unlabeled probe. For all specific oligonucleotides there were no differences in the density of silver grains over dentate granule cells in the nonstimulated side or the stimulated controls (data not shown). Therefore, the results (mean total - mean nonspecific) for each pair of sections were standardized and expressed as the ratio (\%) of the density of grains over dentate granule cells ipsilateral to LTP induction to the density of grains in the contralateral dentate gyrus. Standardized results in the experimental rats (at least $n=3$ at each time point investigated, see above) were analyzed by repeated measures ANOVA.

\section{Results}

LTP

High-frequency stimulation of the perforant path produced LTP of both the field EPSP (Fig. 1A)

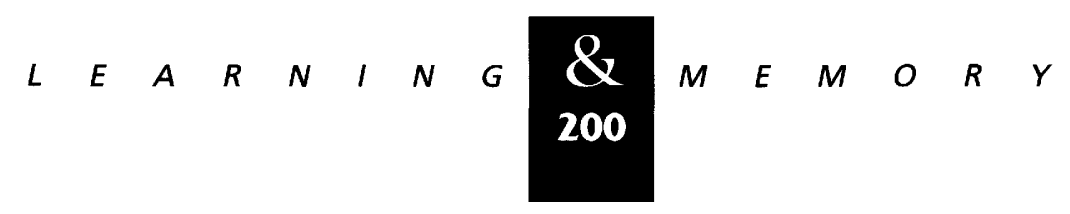


and population spike (Fig. 1B) that lasted for $96 \mathrm{hr}$ after induction. Analysis of variance comparing the mean of the baseline values with a mean of the last 20 min of recording for each rat showed that the magnitude of potentiation was significant [EPSP: $\mathrm{F}(1,30)=17.61, P<0.001 ;$ spike $\mathrm{F}(1,30)=4.41$, $P<0.05]$. Rats that received the tetanic stimulation in the presence of CPP did not express LTP (Fig. 1; EPSP: $\quad \mathrm{F}(1,4)<1 ;$ spike $\mathrm{F}(1,4)=4.79, P>0.05)$. No change was seen in the control animals after pseudotetanus [EPSP: $\mathrm{F}(1,10)<1$; spike $\mathrm{F}(1,10)=2.33, P>0.05]$.

\section{DISTRIBUTION OF NR2 AND MGLUR TRANSCRIPTS}

High levels of NR2A, NR2B, and NR2C expression were seen in hippocampal field of the normal adult (Fig. 2). High-power light field microscopy after high-resolution emulsion autoradiography (not shown) revealed that the expression of NR2A and NR2B was localized predominantly to the dentate granule cells and pyramidal cells of the CA regions, whereas $\mathrm{NR} 2 \mathrm{C}$ transcripts were absent from these neurons. NR2C showed a distinct pattern of expression that correlated with the distribution of glial fibrillary acidic protein (GFAP)-expressing cells in the hippocampus and other brain regions at this coronal level in adjacent sections, and may reflect NR2C mRNA in astrocytes (data not shown). We were unable to detect NR2D expression in the adult rat brain. The very low diffuse signal for NR2D in thalamic regions was not displaced by excess cold NR2D probe and represents a nonspecific signal.

Within the hippocampal fields, mGluR1a, mGluR1b, and mGluR1c all showed the highest expression levels in the dentate granule cells, whereas there was no apparent expression in the CA1 pyramidal cells (Fig. 3). mGluR1a and mGluR1b expression was seen at moderate levels in CA3 pyramidal cells with no apparent signal for mGluR1c in this region. In contrast, the highest levels of mGluR5b expression in the hippocampus was observed in CA1 and CA3 pyramidal cells, wheras only a moderate expression was observed in dentate granule cells (Fig. 3). mGluR5a showed a very low level of expression in dentate granule and CA pyramidal cells of the hippocampus.

\section{NR2, MGLUR1, AND MGLUR5 EXPRESSION DURING LTP MAINTENANCE}

Following tetanic stimulation of the perforant path, there was no significant change in the ex-
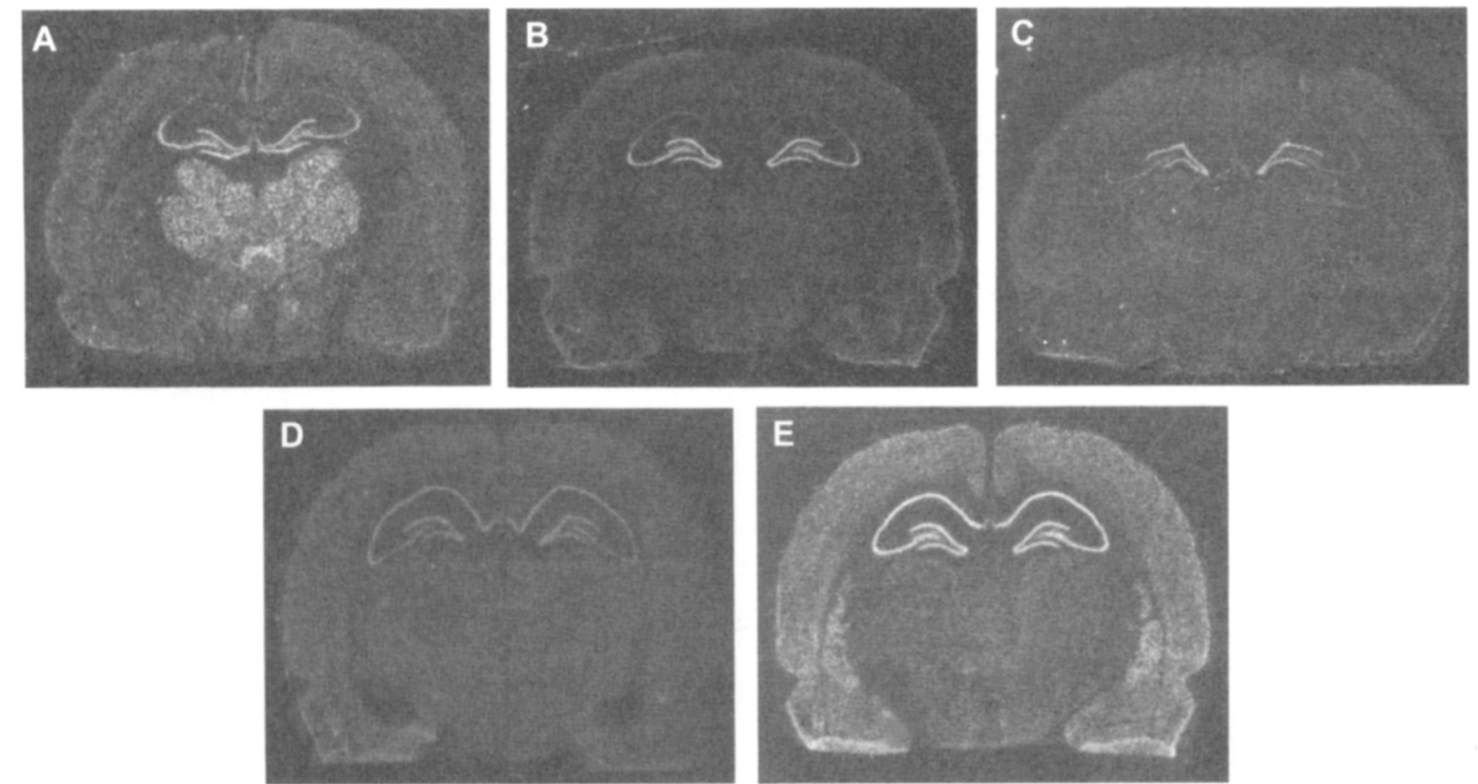

Figure 3: Localization of PLC-coupled mGluR1 expression in the hippocampus. mGluR1a $(A), \mathrm{mGluR} 1 \mathrm{~b}(B), \mathrm{mGluR} 1 \mathrm{c}$ (C), mGluR5a (D), and mGluR5b (E). Moderate levels of mRNA for mGluR1a and mGluR1b was found in the dentate granule cell layer and CA3 region but no signal was seen in CA1. There was moderate expression of $\mathrm{mGluR} 1 \mathrm{c}$ in the dentate gyrus but low expression in CA3. No observable signal for mGluR1c was seen in CA1. There was high levels of mGluR5b expression but low levels of mGluR5a mRNA throughout the neuronal cell layers of the hippocampus.

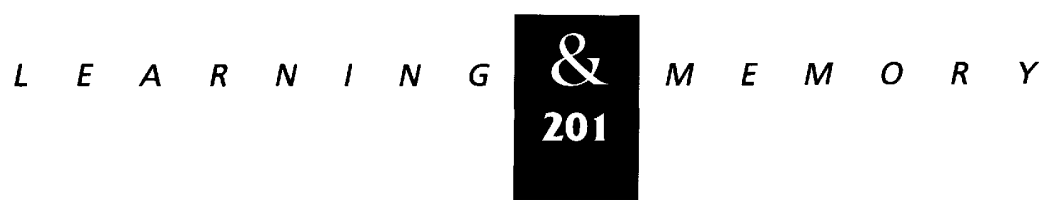


pression of NR2A subunits of the NMDA receptor in dentate granule cells with respect to the contralateral nonpotentiated cells $[\mathrm{F}(1,14)=1.38$; $P>0.05$; Fig 4A]. However, there was an increase in the expression of NR2B subunits in the potentiated granule cells [Fig. $4 \mathrm{~B} ; \mathrm{F}(1,24)=6.51$; $P<0.05]$. This increase showed a temporal pattern where at $24 \mathrm{hr}$ it was starting to increase, peaked and was highly significant at $48 \mathrm{hr}$ (see Fig. 5), and by $96 \mathrm{hr}$, although still slightly elevated, it was no longer significant. NR2C expression in the nonneuronal cells near the ventral blade of the dorsal dentate gyrus was not altered $[F(1,20)=2.03$; $P>0.05]$, and at no time point after induction of LTP was NR2D expression in the granule cells changed (data not shown).

There were no changes in the expression of mGluR 1a $[\mathrm{F}(1,14)=3.70 ; P>0.05]$ and mGluR 1b $[\mathrm{F}(1,18)<1]$ in the dentate granule cells $2,24,48$, or $96 \mathrm{hr}$ following the induction LTP (Fig. 6A,B). However, there was a time-dependent effect of
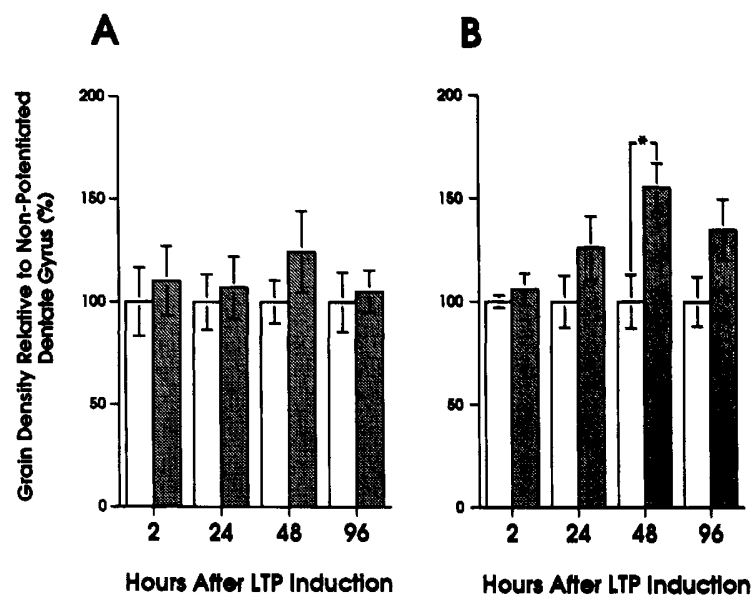

Figure 4: The selective increase in the expression of NR2B subunits of the NMDA receptor in granule cells of the dentate gyrus after unilateral induction of LTP. The density of silver grains in dentate granule cells of the potentiated hemisphere (shaded bars) was expressed as a percentage of the density of silver grains counted in the nonstimulated contralateral dentate gyrus (open bars) generated by radiolabeled DNA probes specific for NR2A $(A)$ and NR2B $(B)$ mRNAs. High-frequency stimulation had no effect on the expression of NR2A at any time point studied after LTP induction. However, $48 \mathrm{hr}$ poststimulation there was an increase in the expression of NR2B NMDA receptor subunits in the ipsilateral dentate granule cells $(* P<0.05)$. The time course of increased expression of NR2B after LTP is identical to that identified previously for NR1 (Thomas et al. 1994a).

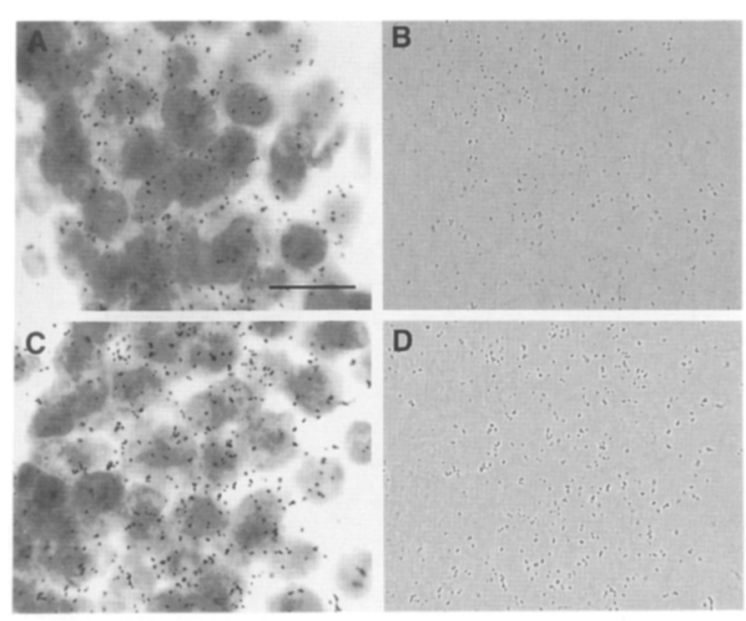

Figure 5: High-power light field photomicrographs showing a typical field chosen from the middle of the ventral blade of the dorsal dentate gyrus to measure the density of silver grains over individual granule cells generated by the hybridization of $\mathrm{a}^{35} \mathrm{~S}$-labeled CDNA probe specific for NR2B over the contralateral $(A, B)$ or potentiated $(C, D)$ hemisphere $48 \mathrm{hr}$ after unilateral LTP induction. $B$ and $D$ are the computer-enhanced (MCID program, Imaging Research Inc.) accentuations of silver grains associated with granule cells shown in $A$ and $C$, respectively. Silver grains were visualized at the cellular level after dipping and exposing the hybridized brain sections in photographic emulsion for 4 weeks before development. The density was assessed for nine granule cells $\left(90 \mu \mathrm{m}^{2}\right)$ in each field. Bar, $10 \mu \mathrm{m}$.

LTP on mGluR1c expression in the dentate gyrus $[\mathrm{F}(1,14)=5.20 ; P<0.05$; Fig. $6 \mathrm{C}]$. This manifested as a slow-onset increase in mRNA for this transcript, commencing at $24 \mathrm{hr}$ but was not increased significantly until $96 \mathrm{hr}$ after LTP. The levels of expression of mGluR5a were too low to quantify accurately, and there was no change in the expression of mGluR $5 b$ in granule cells at any time point after LTP induction $[F(1,14)<1$; Fig. 6D]. The postsynaptic increase in expression of mGluR1c in dentate granule cells 96 hr after LTP was prevented by preadministration of CPP, showing no difference in the level of expression of the mRNA between the stimulated and nonstimulated sides of the dentate gyrus $[\mathrm{F}(1,16)<1$; data not shown].

\section{Discussion}

We have shown the differential expression of NR2 subunits of the NMDA receptor and mGluR1 and mGluR5 splice variants in the adult hippocampus using in situ hybridization and short radiola-

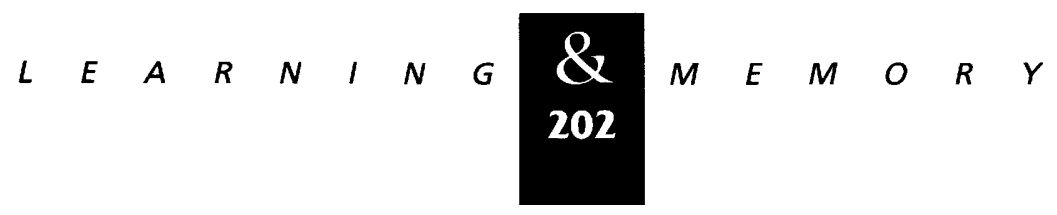




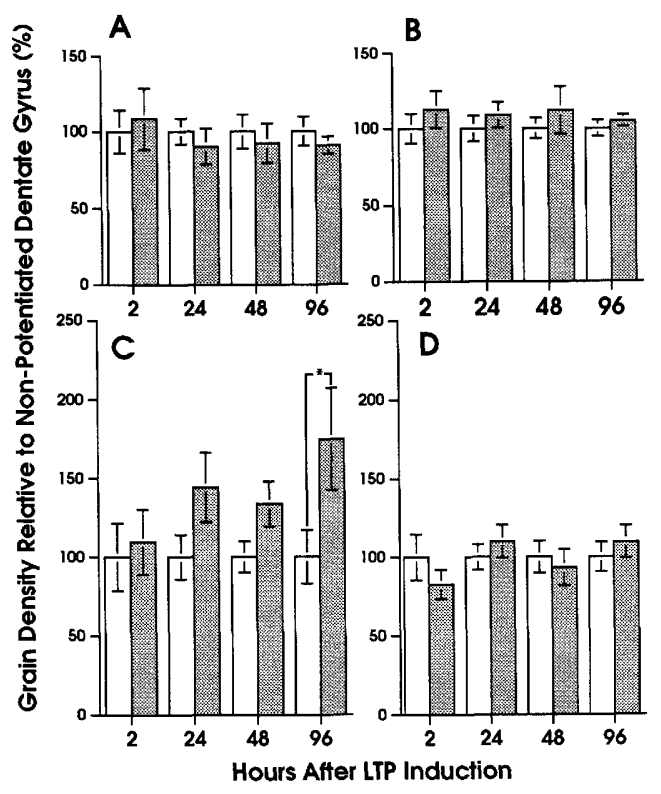

Figure 6: A slow onset but persistent increase in the expression mGluR1c (C) was seen in dentate granule cells that were the postsynaptic targets of perforant path fibers that were tetanized (shaded bars) relative to contralateral side that was not stimulated (open bars). By 96 hr after LTP, this increase was significantly above normal levels of expression $(* P<0.05)$. There were no changes in the expression of mGluR1a $(A)$, mGluR1b $(B)$, or mGluR5b $(D)$ in the granule cells at any time point examined after the induction of LTP.

beled DNA probes. NR2A and NR2B NMDA receptor subunits are expressed highly in the neuronal populations of the hippocampus, whereas NR2C is probably expressed in nonglutamatergic cells. These patterns of expression within the hippocampus are identical to those reported previously (Monyer et al. 1992, 1994). NR2D expression was not detected in the hippocampus or indeed other brain regions. In general, mGluR1 transcripts were found predominantly in the dentate gyrus granule cells but not CA1 pyramidal neurons, whereas mGluR5 transcripts, particularly mGluR5b, were more highly expressed in the CA1 than in dentate gyrus neurons. Earlier reports in which in situ hybridization experiments were carried out using radiolabeled antisense riboprobes that did not distinguish between splice variants of the mGluR1 show lack of expression in the CA1 cells (Masu et al. 1991; Pin et al. 1992). However, we find that mGluR1c had a restricted expression to granule cells of the dentate gyrus. Northern blot experiments have revealed high mGluR5b expression in the hippocampus (Minakami et al. 1993). More- over, the predominance of mGluR5b transcripts relative to mGluR5a transcripts in the adult rat brain has been reported previously (Joly et al. 1995; Romano et al. 1996). In that study the authors were unable to obtain a specific signal with in situ hybridization but did identify mGluR5a transcripts in the brain using RT-PCR, which suggests very low levels of its expression in the adult under normal conditions.

After the induction of LTP at perforant pathdentate granule cell synapses in freely moving rats, we have shown that there is an increase in the postsynaptic expression of selective glutamate receptor subunits, namely the NR2B subunit of the ionotropic NMDA receptor and the mGluR1c splice variant of the metabotropic glutamate receptor. In both cases the up-regulation in mRNA levels showed a long latency, peaking around 48$96 \mathrm{hr}$ after LTP induction. The enhanced levels of NR2B mRNA suggest that the increase is transient, as there was a slow increase across time that peaks at $48 \mathrm{hr}$ and then starts to decline, whereas the increase in mGluR1c expression peaked at $96 \mathrm{hr}$. The fact that blockade of the induction of LTP with the NMDA receptor antagonist, CPP, also blocked any increase in expression of either the NR2B subunit or the mGluR1c subtype, suggests that the expression of these genes is dependent on the induction of LTP and not increased as a consequence of a nonspecific stimulation effect of highfrequency stimulation. Further experiments carried out at longer time points after the induction of LTP would be necessary to determine whether the increase in expression of these genes, at least the mGluR1c, shows a sustained increase in parallel with the duration of LTP, or whether there are several waves of expression of different genes that have different temporal windows and correlate with a cascade of events at different time points during the maintenance of LTP, as is alluded to by the increase in $\gamma \mathrm{PKC}, \alpha$ CaMKII, ERK2, and raf-B (Thomas et al. 1994b) and the NR2B subunit of the NMDA receptor.

The increase in NR2B expression followed the same time course and had the same profile as the increase in the expression of PKC-sensitive NR1 subunits after LTP that we have reported previously (Thomas et al. 1994a). Therefore, not only does the expression of distinct NR1 and NR2 subunits of the NMDA receptor appear to be coregulated by LTP, but these particular NMDA receptor subunits are those that are targets for post-translational modification by phosphorylation.

$$
\begin{array}{llllllll}
L & E & A & R & N & I & N & G \\
\begin{array}{r}
\boldsymbol{Z} \\
\mathbf{2} \\
0
\end{array} & M & E & M & O & R & Y
\end{array}
$$


A consequence of the serine-threonine phosphorylation of NMDA receptor subunits by PKC, presumably on PKC-sensitive NR1 subunits (Tingley et al. 1993), is an enhanced channel conductance of the NMDA receptor (Durand et al. 1992; Kutsawada et al. 1992; Urushihara et al. 1992). Membrane-associated NR2A and NR2B subunits show basal levels of tyrosine phosphorylation in vivo that can undergo further tyrosine phosphorylation events by endogenous tyrosine kinases (Lau and Huganir 1995), possibly in response to various forms of physiological stimulation. For example, electrophysiological studies have demonstrated that one consequence of tyrosine phosphorylation may be an increase in NMDA receptor function (Wang and Salter 1994). The NR2B subunit was found to be the major tyrosine phosphorylated protein in the postsynaptic density in the brain (Moon et al. 1994). These authors suggested that the NR2B subunit may anchor NMDA receptors at the postsynaptic membrane and tyrosine phosphorylation of NR2B could permit the interaction of NMDA receptors with other proteins of the postsynaptic density and create an assembly point for signal transduction complexes. Thus, the modification of NR2B specifically by tyrosine kinases may effect not only NMDA receptor kinetics but its proximity to and association with intracellular signaling proteins. Although tyrosine phosphorylation plays a critical role in LTP (O'Dell et al. 1991; Grant et al. 1992), we do not know yet whether targets for tyrosine phosphorylation include NR2B and what the consequences of NR2B phosphorylation is after LTP.

The transient increase in the expression of NR2B certainly suggests that this NR2 subunit has a particular role in LTP. Changes in the expression of a specific mRNA species with LTP may be correlated with comparable changes in the levels of protein for NR2B at some later time. If so, then one could speculate that modified/modifiable NR2B protein would contribute directly to the late phase maintenance of LTP. Alternatively, increased expression, especially when transient, of a particular mRNA, may reflect a compensatory response if a protein is targeted specifically for modification and breakdown at an earlier time point.

The finding of a slowly developing but persistent increase in mGluR 1c expression may have important ramifications for the long-term storage of synaptic information in the hippocampus. Ultrastructure studies have shown that unlike mGluR 1a (and mGluR5), which is localized to the postsyn- aptic elements at the periphery of postsynaptic densities (Martin et al. 1992; Baude et al. 1993; Romano et al. 1995), the shorter mGluR1b and mGluR1c are also found on nerve terminals, at least in the rat striatum (Fotuhi et al. 1993). Moreover, we have seen mGluR1-like immunoreactivity in the mossy fibers and their terminals as well as in the granule cells themselves and their associated dendritic field (data not shown; antibody was a kind gift from Dr. S. Nakanishi, Kyoto University). At this point we are not able to distinguish whether the increased expression of the gene-encoding mGlulc is restricted to the post- or presynapse or at both locations, but as PLC-coupled mGluRs potentiate glutamate release from synaptosomes (Herrero et al. 1992) and at glutamatergic synapses (McBain et al. 1994), increased mGluR1c expression in the dentate granule cells may correlate with enhanced levels of presynaptic mGluR1c present on mossy fiber terminals and this may function to enhance glutamate release at this site, secondary to the induction of LTP in the perforant path input onto the dentate granule cells. Thus, changes in the postsynaptic expression of proteins that are targeted to the presynaptic terminals during LTP could represent a good candidate mechanism underlying the propagation of long-lasting increases in synaptic strength within hippocampal circuits, a process that would have wide implications for a molecular mechanism involved in learning. Indeed, there is a precedent for both these ideas in previous studies investigating changes in the expression of the presynaptic protein, syntaxin $1 \mathrm{~B}$, which functions in the docking and priming of vesicles for calcium-dependent neurotransmitter release (Südhof 1995) after induction of LTP (Smirnova et al. 1993) and learning (Davis et al. 1996). Smirnova et al. (1993) found a rapid and transient increase in the expression of syntaxin $1 \mathrm{~B}$ in dentate granule cells after the induction of LTP at the perforant path-dentate gyrus synapses. Furthermore, an increase in the syntaxin 1B protein was observed in the terminal field of mossy fibers in CA3. The increase in syntaxin 1B would have profound consequences on the release of neurotransmitter at the axon terminals of dentate granule cells and as such may support the NMDA-independent, trans-synaptically mediated LTP at the mossy fiber-CA3 synapses that has been observed after tetanic stimulation of the perforant path (Yeckel and Berger 1990). It is possible that the mGluR $1 \mathrm{c}$ receptor also may contribute to this form of trans-synaptic plasticity, and, given the 
time course of its expression found here, it may in fact have a crucial role in the maintenance of transsynaptic plasticity downstream in a cascade that is primed by syntaxin.

Transgenic studies have implicated the importance of NR2B and mGluR1 in LTP. Mice that lack functional NR2A subunits do exhibit LTP at CA1 synapses, although the magnitude of the LTP for the given stimulation paradigm was smaller (Sakimura et al. 1995), suggesting that NR2A may not be crucial for LTP at this synapse and NR2B present in the CA1 neurons may be more so. However, NR2B-deficient mice do not live more than a few days unaided (Kutsuwada et al. 1996), suggesting that NR2B has important functions apart from its role in plasticity in the adult brain. Indeed, the gene deletion study indicated that fully functional NR2B was necessary for the appropriate targeting of trigeminal neurons. Nevertheless, the study did show that the NR2B-deficient mice do not support juvenile LTD as do their NR2B-intact littermates. Two reports of mGluR1 knockouts (although not specifically mGluR1c deletion) have suggested that this metabotropic receptor subtype is necessary for the expression of LTP at least at some synapses (Aiba et al. 1994; Conquet et al. 1994). Conquet et al. have found that the absence of mGluR1 was only detrimental on non-NMDA receptor-dependent LTP at the mossy fiber-CA3 synapse. This form of LTP is maintained by presynaptic modifications alone. In contrast, Aiba et al. (1994) showed diminished LTP at CA3 Schaffer collateral-CA1 sites, but concluded that because mGluR1s are absent from CA1 pyramidal cells, the role of mGluR1 would be presynaptic and may reflect a gain control for transmitter release. These transgenic studies are not at odds with the current study in which we see an LTP-associated increase in the expression of a mGluR 1 splice variant of this receptor that can be localized presynaptically. We suggest, further, that mGluR1c may regulate the presynaptic component of some forms of hippocampal LTP.

In summary, we have shown that an increase in the genes encoding selective glutamatergic receptor subunits and subtypes in the dentate gyrus occurs at delayed time points after the induction of LTP in the freely moving rat. The NR2B subunit of the NMDA receptor appears to peak at $48 \mathrm{hr}$, as was shown previously with the PKC-sensitive NR1 subunit (Thomas et al. 1994a), whereas mGluR1c peaks at $96 \mathrm{hr}$. This differential time course suggests that they may be linked within a cascade of consequential events required to maintain the late phases of L'TP. We do not know the exact function of this delayed up-regulation of expression, but it is tempting to speculate, in light of newly emerging data that has suggested that LTP triggers the conversion of silent synapses to functional ones (Isaac et al. 1995; Liao et al. 1995), that these increases in NMDA and mGluR subunits may reflect a molecular mechanism to allow these new synapses to express plasticity.

\section{Acknowledgments}

This study was supported in part by the Human Frontier Science Programme.

\section{References}

Abe, T., H. Sugihara, H. Nawa, R. Shigemoto, N. Mizuno, and S. Nakanishi. 1992. Molecular characterization of a novel metabotropic glutamate receptor mGluR5 coupled to inositol phosphate $/ \mathrm{Ca}^{2+}$ signal transduction. J. Biol. Chem. 267: 13361-13368.

Abraham, W.C., M. Dragunow, and W.P. Tate. 1991. The role of immediate early genes in the stabilisation of long-term potentiation. Mol. Neurobiol. 5: 297-314.

Aiba, A., C. Chen, K. Herrup, C. Rosenmund, C.F. Stevens, and S. Tonegawa. 1994. Reduced hippocampal long-term potentiation and context-specific deficit in associative learning in mGluR1 mutant mice. Cell 79: $365-375$.

Asztely, F., H. Wigstrom, and B. Gustafsson. 1992. The relative contribution of NMDA receptor channels in the expression of long-term potentiation in the hippocampal CA1 region. Eur. J. Neurosci. 4: 681-690.

Bashir, Z.I., S. Alford, S.N. Davies, A.D. Randall, and G.L. Collingridge. 1991. Long-term potentiation of the NMDA receptor mediated synaptic transmission in the hippocampus. Nature 349: 156-158.

Bashir Z.I., Z.A. Bortolotto, C.H. Davies, N. Berretta, A.J. Irving, A.J. Seal, J.M. Henley, D.E. Jane, J.C. Watkins, and G.L. Collingridge. 1993. Induction of LTP in the hippocampus needs synaptic activation of glutamate metabotropic receptors. Nature 363: 347-350.

Baude, A., Z. Nusser, J.D.B. Roberts, E. Mulvihill, R.A.J. Mcllhinnney, and P. Somogyi. 1993. The metabotropic glutamate receptor ( $\mathrm{mGluR} 1 \alpha$ ) is concentrated at perisynaptic membrane of neuronal subpopulations as detected by immunogold reaction. Neuron 11: 771-787.

Ben-Ari, Y. and L. Aniksztejn. 1995. Role of glutamate metabotropic receptors in long-term potentiation in the hippocampus. Sem. Neurosci. 7: 127-135.

Bliss, T.V.P and G.L. Collingridge. 1993. A synaptic model

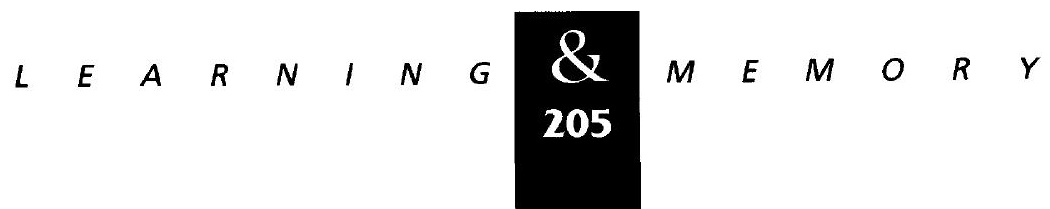




\section{Thomas et al.}

of memory: Long-term potentiation in the hippocampus. Nature 361: 31-39.

Bortolotto, Z.A. and G.L. Collingridge. 1993. Characterisation of LTP induced by the activation of glutamate metabotropic receptors in area CA1 of the hippocampus. Neuropharmacology 32: 1-9.

1995. On the mechanisms of long-term potentiation induced by (1S,3R)-1-aminocyclopentane-1,3-dicarboxylic Acid (ACPD) in rat hippocampal slices. Neuropharmacology 34: 1003-1014.

Chinestra, P., L. Aniksztejn, D. Diabira, and Y. Ben-Ari. 1993. (RS)- $\alpha$-methyl-4-carboxyphenylglycine neither prevents induction of LTP nor anatagonizes metabotropic glutamate receptors in CA1 hippocampal neurons. I. Neurophysiol. 6: 1050-1054.

Cole, A.J., D.W. Saffan, J.M. Baraban, and P.F. Worley. 1989. Rapid increase of an immediate early gene messenger RNA in hippocampal neurons by synaptic NMDA receptor activation. Nature 340: 474-476.

Collingridge, G.L., S.J. Kehl, and H. McLennan. 1983. Excitatory amino acids in synaptic transmission in the Schaffer collateral-commissural pathway of the rat hippocampus. I. Physiol. (Lond.) 334: 33-46.

Conquet, F., Z.I. Bashir, C.H. Davies, H. Daniel, F. Ferraguti, F. Bordi, K. Franz-Bacon, A. Reggianai, V. Matarese, F. Condé, G.L. Collingridge, and F. Crépel. 1994. Motor deficit and impairment of synaptic plasticity in mice lacking mGluR1. Nature 372: 237-243.

Davis, S. and S. Laroche. 1996. Activation of metabotropic glutamate receptors induce differential effects on synaptic transmission in the dentate gyrus and CA1 of the hippocampus in the anaesthetized rat. Neuropharmacology 35: 337-346.

Davis, S., J. Rodger, A. Hicks, J. Mallet, and S. Laroche. 1996. Brain structure and task specific increase in expression of the gene encoding syntaxin $1 \mathrm{~B}$ during learning in the rat: A potential molecular marker for learning induced synaptic plasticity in neural networks. Eur. J. Neurosci. In press.

Dragunow, M., W.C. Abraham, M. Goulding, S.E. Mason, H.A. Robertson, and R.L.M. Faull. 1989. Long-term potentiation and the induction of c-fos mRNA and protein in the dentate gyrus of anaesthetised rats. Neurosci. Lett. 101: 441-442.

Durand, G.M., M.V.L. Bennett, and R.S. Zukin. 1992. Splice variants of the $\mathrm{N}$-methyl-D-aspartate receptor NR1 identify domains involved in regulation by polyamine and protein kinase C. Proc. Natl. Acad. Sci. 90: 6731-6735.

Fitzjohn, S.M., A.J. Irving, M.J. Palmer, J. Harvey, D. Lodge, and G.L. Collingridge. 1996. Activation of group I mGluRs potentiates NMDA responses in rat hippocampal slices. Neurosci. Lett. 203: 211-213.
Fotuhi, M., A.H. Sharp, C.E. Glatt, P.M. Hwang, M. von Krosigk, S.H. Snyder, and T.M. Dawson. 1993. Differential localization of phosphoinositide-linked metabotropic glutamate receptor (mGluR1) and the inositol 1,4,5triphosphate receptor in rat brain. J. Neurosci. 13: 2001-2012.

Frey, U., M. Krug, R. Brodemann, K. Reymann, and H. Matthies. 1989. Long-term potentiation induced in dendrites separated from rats $\mathrm{CA} 1$ pyramidal somata does not establish a late phase. Neurosci. Lett. 97: 135-139.

Gereau, R.W. and P.J. Conn. 1995. Roles of specific metabotropic glutamate receptor subtypes in regulation of hippocampal CA1 pyramidal cell excitability. I. Neurophysiol. 74: 122-129.

Grant, S.G.N., T.J. O’Dell, K.A. Karl, P.L. Stein, P. Soriano, and E.R. Kandel. 1992. Impaired long-term potentiation, spatial-learning and hippocampal development in fyn mutant mice. Science 258: 1903-1910.

Herrero, I., M.T. Miras-Portugal, and J. Sánchez-Prieto. 1992. Positive feedback of glutamate exocytosis by metabotropic presynaptic receptor stimulation. Nature 360: 163-166.

Hicks, A., S. Davis, J. Rodger, A. Helme-Guizon, S. Laroche, and J. Mallet. 1996. Pre- and post-synaptic regulation of synapsin I and syntaxin 1B expression in neuronal networks: Differential effects of neuronal activity and long-term potentiation in vivo. J. Physiol. (Paris) (in press).

Hollmann, M. and S. Heinemann. 1994. Cloned glutamate receptors. Annu. Rev. Neurosci. 17: 31-108.

Isaac, J.T.R., R.A. Nicoll, and R.C. Malenka. 1995. Evidence of silent synapses: Implications for the expression of LTP. Neuron 15: 427-434.

Joly, C., J. Gomeza, I. Brabet, K. Curry, J. Bockaert, and J-P. Pin. 1995. Molecular, functional, and pharmacological characterization of the metabotropic glutamate receptor type 5 splice variants: Comparison with mGluR1. J. Neurosci. 15: 3970-3981.

Klann, E., S-J. Chen, and J.D. Sweatt. 1993. Mechanism of protein kinase $\mathrm{C}$ activation during the induction and maintenance of long-term potentiation probed using a selective peptide substrate. Proc. Natl. Acad. Sci. 90: $8337-8341$.

Kutsawada, T., N. Kashiwabi, H. Mori, K. Sakimura, E. Kushiya, K. Araki, H. Meguro, H. Masaki, T. Kumanishi, M. Arakawa, and M. Mishina. 1992. Molecular diversity of the NMDA receptor. Nature 358: 36-41.

Kutsawada T., K. Sakimura, T. Manabe, C. Takayama, N. Katakura, E. Kushiya, R. Natsume, M. Watanabe, Y. Inoue, T. Yagi, S. Aizawa, M. Arakawa, T. Takahashi, Y. Nakamura, H. Mori, and M. Mishina. 1996. Impairment of suckling response, trigeminal neuronal pattern formation, and 
hippocampal LTD in NMDA receptor $\epsilon 2$ subunit mutant mice. Neuron 16: 333-344.

Laroche, S., V. Doyère, and V. Bloch. 1989. Linear relationship between the magnitude of long-term potentiation in the dentate gyrus and associative learning in the rat. A demonstration using commissural inhibition and local infusion of an $\mathrm{N}$-methyl-d-aspartate receptor antagonist. Neuroscience 28: 375-386.

Lau, L.-F. and R.L. Huganir. 1995. Differential tyrosine phosphorylation of $\mathrm{N}$-methyl-d-aspartate receptor subunits. J. Biol. Chem. 270: 20036-20041.

Liao, D., N.A. Hessler, and R. Malinow. 1995. Activation of postysnaptically silent synapses during pairing-induced LTP in CA1 region of hippocampal slice. Nature 375: 400-404.

Lynch, M.A., K.L. Voss, J. Rodriguez, and T.V.P. Bliss. 1994. Increase in synaptic vesicle proteins accompanies long-term potentiation in the dentate gyrus. Neuroscience 60: $1-5$.

McBain, C.J., T.J. DiChiara, and J.A. Kauer. 1994. Activation of metabotropic glutamate receptors differentially affects two classes of hippocampal interneurons and potentiates excitatory synaptic transmission. J. Neurosci. 14: 4433-4445.

Malenka, R.C., J.A. Kauer, D.J. Perkel, M.D. Mauk, P.T. Kelly, R.A. Nicoll, and M.N. Waxham. 1989. An essential role for postsynaptic calmodulin and protein kinase activity in long-term potentiation. Nature 340: 554-556.

Malinow, R., H. Schulman, and R.W. Tsien. 1989. Inhibition of postsynaptic PKC or CaMKII blocks induction but not expression of LTP. Science 245: 862-866.

Manahan-Vaughan, D. and K.G. Reymann. 1995. 1S,3R-ACPD dose-dependently induces a slow-onset potentiation in the rat hippocampal CA1 region in vivo. Neuropharmacology 34: 1103-1105.

Manzoni, O.J., M.G. Weisskopf, and R.A. Nicoll. 1994. MCPG anatgonizes metabotropic glutamate receptors but not long-term potentiation in the hippocampus. Eur. J. Neurosci. 6: $1050-1054$.

Martin, L.J., C.D. Blackstone, R.L. Huganir, and D.L. Price. 1992. Cellular localization of a metabotropic glutamate receptor in rat brain. Neuron 9: 259-270.

Masu, M., Y. Tanabe, K. Tsuchida, R. Shigemoto, and S. Nakanishi. 1991. Sequence and expression of a metabotropic glutamate receptor. Nature 349: 760-765.

Minakami, R., F. Katsuki, and H. Sugiyama. 1993. A variant of metabotropic glutamate receptor subtype 5: An evolutionally conserved insertion with no termination codon. Biochem. Biophys. Res. Comm. 194: 622-627.

Monyer, H., R. Spengel, R. Schoepfer, A. Herb, M. Higuchi, H. Lomeli, N. Burnashev, B. Sakmann, and P.H. Seeburg.
1992. Heteromeric NMDA receptors: Molecular and functional distinction of subtypes. Science 256: 1217-1221.

Monyer, H., N. Burnashev, D.J. Laurie, B. Sakmann, and P.H. Seeburg. 1994. Developmental and regional expression in the rat brain and functional properties of four NMDA receptors. Neuron 12: 529-540.

Moon, I.S., M.L. Apperson, and M.B. Kennedy. 1994. The major tyrosine-phosphorylated protein in the postsynaptic density fraction is $\mathrm{N}$-methyl-d-aspartate receptor subunit $2 \mathrm{~B}$. Proc. Natl. Acad. Sci. 91: 3954-3958.

Mori, H. and M. Mishina. 1995. Structure and function of the NMDA receptor channel. Neuropharmacology 34: 1219-1237.

Muller, D., M. Joly, and G. Lynch. 1988. Contributions of quisqualate and NMDA receptors to the induction and expression of LTP. Science 242: 1694-1697.

Musgrave, M.A., B.A. Ballyk, and J.W. Goh. 1993. Coactivation of metabotropic and NMDA receptors is required for LTP induction. Neuroreport 4: 171-174.

O'Connor, J.J., M.J. Rowan, and R. Anwyl. 1994. Long-lasting enhancement of NMDA receptor-mediated synaptic transmission by metabotropic glutamate receptor activation. Nature 367: 557-559.

1995. Tetanically induced LTP involves a similar increase in the AMPA and NMDA receptor components of the excitatory postsynaptic current: Investigations of the involvement of mGlu receptors. J. Neurosci. 15: 2013-2020.

O'Dell, T.J., E.R. Kandel, and S.G.N. Grant. 1991 Long-term potentiation in the hippocampus is blocked by tyrosine kinase inhibitors. Nature 14: 558-560.

Otani, S. and W.C. Abraham. 1989. Inhibition of protein synthesis in the dentate gyrus but not entorhinal cortex blocks the maintenance of long-term potentiation in rats. Neurosci. Lett. 106: 175-180.

Pin, J-P. and J. Bockaert. 1995. Get receptive to metabotropic glutamate receptors. Curr. Opin. Neurobiol. 5: 342-349.

Pin, J-P and R. Duvoisin. 1995. The metabotropic glutamate receptors: Structure and functions. Neuropharmacology 34: 1-26.

Pin, J-P., C. Waeber, L. Prezeau, J. Bockaert, and S.F. Heinemann. 1992. Alternative splicing generates metabotropic glutamate receptors inducing different patterns of calcium release in Xenopus oocytes. Proc. Natl. Acad. Sci. 89: 10331-10335.

Richter-Levin, G., M.L. Errington, H. Maegawa, and T.V.P. Bliss. 1994. Activation of metabotropic glutamate receptors is necessary for long-term potentiation in the dentate gyrus and for spatial learning. Neuropharmacology 33: 853-857.

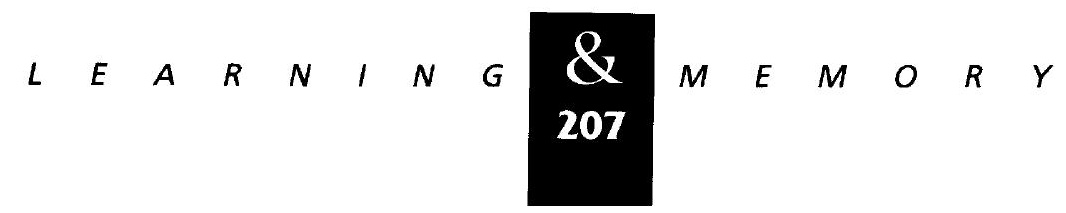




\section{Thomas et al.}

Riedel, G., G. Casabona, and K.G. Reymann. 1995. Inhibition of long-term potentiation in the dentate gyrus of the freely moving rat by the metabotropic glutamate receptor antagonist MCPG. I. Neurosci. 15: 87-98.

Romano, C., M.A. Sesma, C.T. McDonald, K. O'Malley, A.N. Van Den Pol, and J.W Olney. 1995. Distribution of metabotropic glutamate receptor mGluR5 immunoreactivity in rat brain. J. Comp. Neurol. 355: 455-469.

Romano, C., A.N. Van Den Pol, and K.L. O'Malley. 1996. Enhanced early developmental expression of the metabotropic glutamate receptor mGluR5 in rat brain-protein, messenger RNA splice variants and regional distribution. I. Comp. Neurol. 367: 403-412.

Sakimura, K., T. Kutsawada, I. Ito, T. Manabe, C. Takayama, E. Kushiya, T. Yagi, S. Aizawa, Y. Inoue, H. Sugiyama, and M. Mishina. 1995. Reduced hippocampal LTP and spatial learning in mice lacking NMDA $€ 1$ subunit. Nature 373: 151-155.

Seeburg, P.H. 1993. The molecular-biology of mammalian glutamate receptor channels. Trends Neurosci. 16: 359-365.

Selig, D.K., H-K Lee, M.F. Bear, and R.C. Malenka. 1995. Reexamination of the effects of MCPG on hippocampal LTP, LTD and depotentiation. J. Neurophysiol. 74: 1075-1082.

Smirnova, T., S. Laroche, M.L. Errington, A.A. Hicks, T.V.P. Bliss, and J. Mallet. 1993. Transsynaptic expression of a presynaptic glutamate receptor during hippocampal long-term potentiation. Science 262: $433-436$.

Südhof, T.C. 1995. The synaptic vesicle cycle: A cascade of protein-protein interactions. Nature 375: 645-653.

Tanabe, Y., M. Masu, T. Ishii, R. Shigemoto, and S. Nakanishi. 1992. A family of metabotropic glutamate receptors. Neuron 8: 169-179.

Thomas, K.L., S. Davis, S. Laroche, and S.P. Hunt. 1994a. Regulation in the expression of NR1 NMDA glutamate receptor subunits during hippocampal LTP. NeuroReport 6: 119-123.

Thomas, K.L., S. Laroche, M.L. Errington, T.V.P. Bliss, and S.P. Hunt. 1994b. Spatial and temporal changes in signal transduction pathways during LTP. Neuron 13: 737-745.

Tingley, W.G., K.W. Roche, A.K. Thompson, and R.L. Huganir. 1993. Regulation of NMDA receptor phosphorylation by alternative splicing of the c-terminal domain. Nature 364: 70-73.

Urushihara, H., M. Tohda, and Y. Nomura. 1992. Selective potentiation of $\mathrm{N}$-methyl-d-aspartate-induced current by protein kinase $C$ in Xenopus oocytes injected with rat brain RNA. I. Biol. Chem. 267: 11667-11700.

Wang, Y.T and M.W. Salter. 1994. Regulation of NMDA receptors by tyrosine kinases and phosphatases. Nature 369: 233-235.
Wisden, W., M.L. Errington, S. Williams, S.B. Dunnett, C. Waters, D. Hitchcock, G. Evans, T.V.P. Bliss, and S.P. Hunt. 1990. Differential expression of immediate early gene in the hippocampus and spinal cord. Neuron 4: 603-614.

Wisden, W., B.J. Morris, and S.P. Hunt. 1991. In situ hybridization with synthetic DNA probes. In Molecular neurobiology: A practical approach (ed. J. Chad and $\mathrm{H}$. Wheal), pp. 206-225. Oxford University Press, Oxford, UK.

Yeckel, M.F. and T.W. Berger. 1990. Feedforward excitation of the hippocampus by afferents from the entorhinal cortex: Redefinition of the role of the tri-synaptic pathway. Proc. Natl. Acad. Sci. 87: 5832-5836.

Received June 28, 1996; accepted in revised form July 31, 1996. 


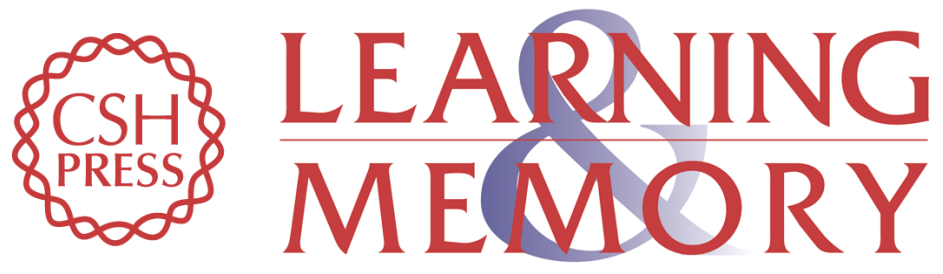

\section{Alterations in the expression of specific glutamate receptor subunits following hippocampal LTP in vivo.}

K L Thomas, S Davis, S P Hunt, et al.

Learn. Mem. 1996, 3:

References This article cites 72 articles, 15 of which can be accessed free at: http://learnmem.cshlp.org/content/3/2-3/197.full.html\#ref-list-1

License

Email Alerting

Receive free email alerts when new articles cite this article - sign up in the box at the Service top right corner of the article or click here. 